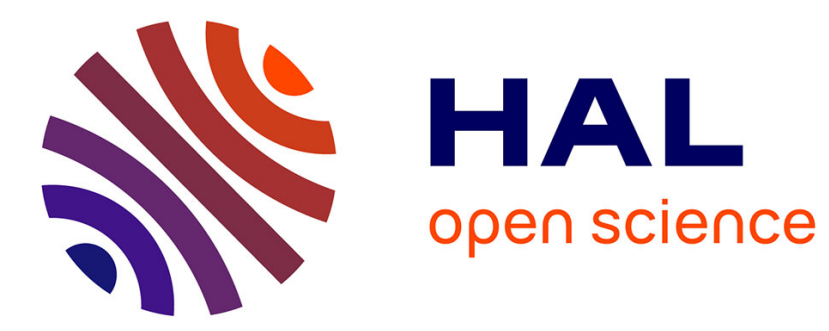

\title{
A review of some suppressed accelerator tube installations
}

\author{
D.M. Shepherd
}

\section{To cite this version:}

D.M. Shepherd. A review of some suppressed accelerator tube installations. Revue de Physique Appliquée, 1977, 12 (10), pp.1521-1524. 10.1051/rphysap:0197700120100152100 . jpa-00244360

\section{HAL Id: jpa-00244360 https://hal.science/jpa-00244360}

Submitted on 1 Jan 1977

HAL is a multi-disciplinary open access archive for the deposit and dissemination of scientific research documents, whether they are published or not. The documents may come from teaching and research institutions in France or abroad, or from public or private research centers.
L'archive ouverte pluridisciplinaire HAL, est destinée au dépôt et à la diffusion de documents scientifiques de niveau recherche, publiés ou non, émanant des établissements d'enseignement et de recherche français ou étrangers, des laboratoires publics ou privés. 


\title{
A REVIEW OF SOME SUPPRESSED ACCELERATOR TUBE INSTALLATIONS
}

\author{
D. M. SHEPHERD \\ Megavolt Ltd., Cornhill, Ilminster, Somerset, TA 19, OAH, \\ Great Britain
}

\begin{abstract}
Résumé. - Ce rapport est un résumé des performances d'installation d'accélérateur typique, avec lesquelles nous avons été concernés et où un tube à suppression d'électrons est maintenant installé. Notre commentaire portera sur les points suivants : les raisons pour disposer d'un tube à suppression d'électrons, les paramètres de la réalisation, choix d'une suppression magnétique en électrostatique, les performances des accélérateurs avant et après l'installation du tube à suppression et les autres avantages dûs à l'utilisation d'un tube à suppression.
\end{abstract}

Abstract. - Since its formation in 1965 the company, (under licence from the United Kingdom Atomic Energy Authority and the Science Research Council of Great Britain), has designed, manufactured, and supplied a considerable number of suppressed accelerator tubes for various makes and types of Single Ended and Tandem Van de Graaff accelerators and High Voltage sets in the United Kingdom and overseas.

The theory and principles of electrostatic and magnetic types of suppression for accelerator tubes are well reported elsewhere $[1,2]$ but this report summarizes the performances of typical accelerator installations with which we have been involved and where a suppressed tube is now installed. As and where appropriate we comment on

1) The reasons for having a suppressed tube.

2) The design parameters - choice of magnetic or electrostatic suppression.

3) The accelerator's performance before and after the suppressed tube installation.

4) Other benefits from the use of a suppressed tube.

The review is compiled from company records and user reports.

1. Introduction. - New and reconditioned tubes have been supplied to a number of National Laboratories and University Departments in all parts of the world and the conventional standard types of waisted and baffled tubes are familiar to most accelerator users. Any tube that is not wide open throughout its length is a suppressed tube and the waisted and baffled tubes are early attempts to overcome the now familiar $\mathrm{X}$-ray loading problem. By suppressed tubes we mean here, tubes that have been provided some integral form of electrostatic or magnetic fields to suppress the electron streams which result in X-rays. The construction techniques of accelerator tubes have changed little since the 1950 's, until the recent advent of the diffusion bonded tube; what has changed during this period of course is tube design ideas and the waisted and baffled designs though still used, now have their place in history. The successful use of electrostatic or magnetic suppressed tube designs have not been widely reported or exploited for use in EXISTING types of High Voltage machines. Design specifications for many machines are often not fully satisfied or are only achieved at the expense of ion beam current or maximum voltage.

The early 60 's saw the development of the electros- tatic and magnetic suppressed tubes independently at the U.K.A.E.A. Establishments Aldermaston and Harwell and at H.V.E.C. in the U.S.A. and from these early developments the company manufacturing under licence has designed, constructed and supplied tubes of both types to various laboratories. A brief resume of various installations follows in the expectation that other High Voltage Accelerator Laboratories may be encouraged to improve their machines with-out the complications and costly conversions necessary to accomodate the diffusion bonded type tubes. The case histories that follow cover a range of machines and for convenience have been arranged in chronological order.

Case 1. 5.5. MeV Van de Graaff - Model C.N. UNIVERSITY OF MANCHESTER, U.K.

The first two tubes used in this machine from 19571962 were standard H.V.E.C. (2 sections) tubes which records show have an average life of just less than 5000 hours each over the 5 year running period (approximately 2000 hours per annum) with a maximum voltage of $6 \mathrm{MV}$.

The inclined field (I.F.) tube installed in 1962 is still in use today and has amassed a total of 30000 hours 
over the 15 year period (again approximately 2000 hours per annum) with a maximum voltage of 6.5 MV easily achieved. The X radiation background was reportedly reduced by a factor of 10 at that time.

Ion beams of the isotopes of hydrogen and helium are in constant use with analysed ion beam currents of $15 \mu \mathrm{A}$ typical. Energy changes from $0.5 \mathrm{MeV}$ to 6.5 MeV are carried out routinely - the overall stability and ease of operation is impressive.

This early I.F. tube was developed for use in the Oxford $10 \mathrm{MeV}$ Van de Graaff project [3, 4] (case 2.) and the now familiar Spiral I.F. tube was born. Although this initial I.F. tube was designed and built by S.R.C. at Harwell this company has since supplied a spare of the same design which has not as yet been needed!

\section{Case 2. $10 \mathrm{MeV}$ Van de GraAfF - University of OXFORD U.K.}

This Single Ended, reverse polarity, Van de Graaff became operational in 1966. The need for some improved form of accelerator tube to allow this machine to operate positive and negative (the latter for coupled operation with a H.V.E.C. model E.N. Tandem) at $10 \mathrm{MV}$ was evident from the outset and was tackled by the S.R.C. group as described [3, 4] (see also cases 1. and 3.). A detailed report of this machine's tube experiences has since been made [5] and this machine's tube development programme always closely linked with that of the associated E.N. Tandem.

From the commissioning stage suppressed tubes of electrostatic and magnetic designs and combinations of both types of suppression have been used. The tube which is $13^{\prime \prime}$ O.D. and $20 \mathrm{ft}$ in length $\left(11 / 2^{\prime \prime}\right.$ pitch) is divided into two sections at the intershield. While good results have been obtained with both systems for the high energy tube - no completely satisfactory results for the low energy tube have been achieved. As various tube designs were put to the test the maximum voltage of the machine gradually increased.

Many tubes operated close to rated limit initially, but in general all tubes subsequently deteriorated at varying rates. Most tubes seemed to suffer from severe interelectrode arcing and with glass insulators collecting appreciable aluminium deposits, useful operation was eventually curtailed. With two exceptions, all high energy tubes have been of the Spiral I.F. type with varying forms of electrode design details. Today, however, the high energy tube in use is still of the Spiral I.F. type.

Many ideas for the low energy tube have been tried, ranging from unsuppressed through Spiral I.F. and magnetic and combinations of each to the tube currently in use which is constructed with titanium electrodes and some magnets. The $11 / 2^{\prime \prime}$ pitch has been reduced, with double the number of electrodes (i.e. half pitch) used in the tube construction.
This combination of titanium L.E. tube and Spiral I.F. H.E. tube is operating at 9.6 MV.

Plans to convert this machine to a Folded Tandem are very well advanced and tubes based on half pitch titanium electrode construction are planned for the initial operation.

CASE 3. $12 \mathrm{MeV}$ TANDEM - MOdel E.N. - UnIVERSITY OF OXFORD U.K.

The initial set of H.V.E.C. straight tubes supplied with this machine in 1964 were removed, practically unused, to allow the installation of the first set of Spiral I.F. tubes as part of the tube development programme for the $10 \mathrm{MeV}$ Van de Graaff (case 2.).

This first set of tubes operated for 6000 hours and $\mathrm{X}$-ray levels were approx. $100 / 200 \mathrm{mR} / \mathrm{h}$. Transmission efficiencies were high and terminal voltages approaching $7 \mathrm{MV}$ reached. These tubes were designed and constructed at U.K.A.E.A. Harwell.

Improvements to the electrode design by the university were incorporated in a second set of tubes constructed by the company which then operated for 28000 hours for the L.E. tubes and 13000 hours for the H.E. tubes. X-ray levels were also further reduced to $<10 \mathrm{mR} / \mathrm{h}$.

Further changes in the electrode design which seemed desirable were tried and proved to be unsatisfactory. The second set design has since been developed a little further by the university to increase the life of the H.E. tubes by improvement to the tube insulators.

This set of tubes has been rebuilt a number of times by the company as routine refurbishing or to incorporate improvements and are currently in use. Running hours for all sections exceed 17000 hours. X-ray levels of $100 \mathrm{mR} / \mathrm{h}$ are given as maximum under normal conditions.

During the years the heavy ion use has increased substantially and ions to mass 127 are available with analysed beam currents approaching double figures in some instances.

\section{Case 4. 8 MeV tandem C.I.S.E. Milan, Italy.}

This machine was converted from a Single Ended Van de Graaff to a Tandem machine [6] during the late sixties and the first unsuppressed tubes were designed and supplied by A.W.R.E. Aldermaston and were of the baffled type. Initial machine runs were made with typical unsuppressed tube results and conditions.

Initial interest in suppressed tubes followed from discussions during 1970. Magnetic suppression was chosen since reasonable tubes existed for conversion but, in the event, to eliminate delays to the new installation programme it was decided that the suppression magnets would be supplied for external fitting and to this day remain installed in that manner. Early records of the unsuppressed tubes performance are not available but a note exists which states that at 
3.8 $\mathrm{MV}$ and $8 \mu \mathrm{A}{ }^{1} \mathrm{H}$ beam the X-ray levels were reduced by a factor of 10 when the suppression magnets were fitted. The unfortunate breakdown of this machine which occurred in June 1972 makes comparison of previous running conditions with today's figures difficult. Present reported ${ }^{1} \mathrm{H}$ conditions are $0.3 \mathrm{mR} / \mathrm{h}$ at $3 \mathrm{MV}$ with $3 \mu \mathrm{A}$ ion beam on target. Larger beam currents not normally required, though transmission efficiencies of $50 \%$ at higher beam and voltage conditions are recorded. Recent tests of $16 \mathrm{O}$ beams have produced $0.5 \mu \mathrm{A}$ of $5+16 \mathrm{O}$ at $21 \mathrm{MeV}$ on target.

It is interesting to note that the main vacuum pumps on this machine are of the turbo molecular type.

\section{Case 5. 6 MeV Van de GraAfF - United Kingdom} ATOMIC ENERGY AUTHORITY, HARWELL, U.K.

With one exception this machine has operated since its remodelling in 1968 with magnetically suppressed tubes. The tube is $13^{\prime \prime}$ O.D. and $13 \mathrm{ft}$ long (1 $1 / 2^{\prime \prime}$ pitch). The first two tubes, magnetically suppressed, due to A.W.R.E. Aldermaston, handled all ion beams without difficulty. X-ray levels were substantially zero. Both tubes lasted well in excess of 6500 hours with maximum voltage levels of $4.8 \mathrm{MV}$ recorded, although machine insulator problems created tube damage which in the event limited the maximum voltage. Despite many shorted sections of the tube, due to aluminium deposits on the tube insulators in the case of the first tube, beam transmission was unaffected. The second tube design overcame the insulator problem but the tube did not operate successfully at the high voltages due to interelectrode arcing between the stainless steel inserts used to define the beam path and shield the insulator surface.

Whilst plans for the next generation of tubes were under consideration a conventional waisted tube was constructed by the company to a Harwell design during 1972. During its lifetime - again 6300 hours - the maximum voltage of the machine was increased to $5.8 \mathrm{MV}$. X-ray loading problems did arise which were sufficiently checked by electrostatic suppression in the high energy standpipe to allow useful running to continue.

Following discussions with Harwell the second A.W.R.E. magnetic tube was rebuilt with various modifications incorporated and this tube installed in late 1973. Limitations imposed during this tubes' early life were now removed and maximum voltage of 5.2 MV reached during its 6500 hours life - again X-ray levels Nil and handling and beam transmission satisfactory. During its life time the tube insulators suffered considerable electrical damage at the high energy end which finally limited its usefulness.

The overall performance was, however, sufficiently satisfactory to promote the complete rebuild of the first A.W.R.E. magnetic tube as an exact copy but also incorporating a modification to the tube insula- tors. This second rebuilt tube with close to 6000 hours to its credit has suffered very little electrical damage to the insulators. The first rebuilt tube has since been reconditioned and is standing by as the spare.

Ions to mass 56 are in regular use but the mass/energy product of the $90^{\circ}$ magnet limits the top voltage for the heavier ions. For some metallic ions a second $10^{\circ}$ magnet is used to overcome this energy limit. Analysed ion beam currents of $100 \mu \mathrm{A}$ are possible for some species.

Five tubes used over nine years at 6500 hours average, indicates the extent of the running programme, which demands reliable tubes.

CASE 6. $12 \mathrm{MeV}$ TANDEM - MOdel E.N. - UniverSITY OF UPPSALA, SWEDEN.

This machine installed in 1970 was initially equipped with H.V.E.C. - I.F. tubes, which are recorded as having run for 30000 hours during their 3 years life time and were capable of holding $6 \mathrm{MV}$ terminal voltage. Following discussions early in 1973 a set of magnetically suppressed tubes were required since our present tube performs very badly and the new tubes were supplied in two stages. The high energy tubes were installed first, in August 1974 when it soon became obvious that the machine was limited by the remaining I.F. low energy tubes. New low energy tubes were ordered October 1974 and subsequently installed January 1976 and to date have clocked up 13000 hours. Maximum terminal voltage has been raised to $6.2 \mathrm{MV}$ and ions to mass 16 accelerated with little voltage degradation. Transmission efficiencies reported are $53 \%$ for isotopes of hydrogen to $30 \%$ for ions to mass 16 . For the higher masses of $19 \mathrm{~F}$ and ${ }^{32} \mathrm{~S}$ - at terminal voltage of $5 \mathrm{MV}$ the transmission efficiency is reported as $38 \%$. It is interesting to note that this machine is wholely turbo-molecular pumped.

Case 7. 3 MeV Van de GraAfF - Model K.N. 3.000 NATIONAL PHYSICAL LABORATORY, TEDDINGTON, U.K.

This Single Ended Van de Graaff installed in 1963 has operated well, with the standard H.V.E.C. tubes regularly turning in $3.8 \mathrm{MV}$ and isotopic hydrogen beams of $100 \mu \mathrm{A}$ analysed. The radiation levels in the machine room have, however, been as high as $7 \mathrm{R} / \mathrm{h}$ and in certain circumstances these high levels have seriously affected the accurate measurement work consistent with a National Standard Laboratory. When used to accelerate electrons of $100 \mu \mathrm{A}$ at 3.0 MV X-ray levels approached $10 \mathrm{R} / \mathrm{h}$. Typical tube life of 5000 hours is normally demanded and tubes which eventually fail to hold 3.3 MV are generally discarded. Conventional diffusion pumping is used throughout the system - base pressures $1 \times 10^{-6}$ torr. Tube beams are estimated to be in the order of $300 / 400 \mu \mathrm{A}$.

Discussions on a suppressed tube commenced early in 1974 from which the company recommendation to use a Spiral I.F. tube was accepted. The final design 
was based on previous successes with Single Ended machines and the new tube delivered January 1975. Installation of the tube took place late 1976 and, although only 200 hours are so far recorded, the performance of the Spiral I.F. has been first class. For 3.8 MV and beam conditions as described above the $\mathrm{X}$-ray background is typically $1 \mathrm{R} / \mathrm{h}$ - a reduction of $85 \%$. Machine stability is considerably improved and current balances are now an every day occurrence. User demands to date have not tested the tube to full beam load but all indications so far are very favourable.

CASE 8. $450 \mathrm{kV}$ COCKCROFT-WALTON SET - UNITED KINGDOM ATOMIC ENERGY AUTHORITY, HARWELL, U.K.

The Cockcroft-Walton set was remodelled for Ion Implantation work in 1968 and a 13" O.D. $\times 6 \mathrm{ft}$ long unsuppressed tube with beam aperture of $4^{\prime \prime}$ dia. installed. When this tube suffered a mechanical failure in 1975 it was subsequently rebuilt as a magnetically suppressed tube though to date this tube has not been installed. Normal running of the machine (approx. 2000 hours per annum) results in high-radiation backgrounds under certain conditions and because of machine siting some work has to be scheduled for silent hours when the building can be sealed and personnel entry controlled. Planned additions to the machines' already large range of available ions are likely to aggravate these restricted operating conditions. Ions accelerated range from ${ }^{1} \mathrm{H}$ to ${ }^{209} \mathrm{Bi}$ with analysed beams up to $50 \mu \mathrm{A}$. The tube however frequently accelerates beams resulting from the source support gas used in many instances. This unwanted beam is well in excess of $100 \mu \mathrm{A}$. The fitting of a suppressed tube will, however, prevent these high radiation fields from arising and ease considerably the machine scheduling.

2. Conclusions. - The case histories here described show clearly that the suppressed tube (magnetic or electrostatic) has a place in the existing Van de Graaff type of machines. The reasons for using a suppressed tube are not always necessarily to obtain high voltages. Many installations do achieve the stated ratings and some certainly exceed that — but at a price! Each installation has a built-in limit as far as voltage is concerned due to plant design dimensions and in very many cases a machine without a tube will reach voltages well above what it can achieve when a tube is installed. The advantages of diffusion bonded tubes are not in dispute and for any large new accelerator, provision for their use is sensible, but as some laboratories have found, the cost of converting an existing machine to accept diffusion bonded tubes is not insignificant. In some cases it is not even a practical possibility. To instal a suppressed tube of the types described, however, is not a problem and such tubes cost only a little more than our own standard tubes.

The Spiral I.F. tube has a number of unique design features in its favour compared with other designs of I.F. tubes : High beam transmission - long life uniform suppression of secondaries.

The magnetic tube also has distinct design advantages even over the Spiral I.F. tube. Its construction is considerably simpler and magnetic tubes are less costly. Shorted sections of tube or column do not effect the output beam as is the case with the I.F. tubes.

With the X-ray load removed from a machine the additional operating benefits are many - improved stability, reduced belt charge, less high voltage breakdowns, more healthy environment, increased high voltage a distinct possibility - to name a few.

Acknowledgements. - The author would like to thank all those who took the trouble to complete our User Reports without which this article could not have been written. Thanks are also due to company staff and employees who contributed in many ways.

\section{References}

[1] ALLEN W. D., NIRL/R/21 Rutherford Laboratory (1962).

[2] Howe F. A., IEEE Trans. Nucl. Sci. NS-14 (1967) 3.

[3] Electrostatic Generator Group - Progress Report NILRL/R/23.

[4] Allen W. D., RHVM Dawton Electrostatic Generator Group Final Report RHEL/R120.
[5] MCK. Hyder H. R., Doucas G., Experiences with suppressed accelerator tubes.

[6] Cristofori F., et al, The CISE Tandem Van de Graaff Accelerator - CISE-N-176.

[7] Howe F. A., IEEE Trans. Nucl. Sci. NS-16 (1969) 98. 